\title{
A Course in Flow Visualization: the Art and Physics of Fluid Flow
}

\author{
Jean Hertzberg, Alex Sweetman \\ Dept. Mechanical Engineering/ Dept. Fine Arts \\ University of Colorado \\ Boulder CO 80309
}

\begin{abstract}
In Spring 2003, a new experimental course on flow visualization was offered to a mixed class of Fine Arts Photography and Engineering students. Course content included fluid flow physics, history of photography with respect to the relationship of science and art, as well as flow visualization and photography techniques. Issues such as "What makes an image art? What makes an image scientific?" were addressed. The class focused on studio/laboratory experiences for mixed teams of students.

A range of fluids apparatus were made available, and students also created novel flows. Writeups were required for each image (to the art students' shock). Student work was evaluated for both artistic and scientific merit.

This course represents a radical departure from normal engineering curricula; typically all fine arts studio courses are specifically excluded. However, the course proved to be very successful in attracting both graduate and undergraduate students, engineering women in particular. One outcome of the course is the recognition by students of the beauty of fluid physics that surrounds us each day, leading to motivation for life-long learning.
\end{abstract}

\section{Introduction}

The growing disconnect between engineers and the general public has been a topic for recent discussion and concern. On one side, we can work to educate the public about engineering, and on the other, we can educate our students to relate their studies to a greater world. A diverse student population is important in this context. Typical engineering curricula place heavy emphasis on science and engineering topics. A small dose of humanities and social science are also required, but there is little overlap of concepts. Similarly, humanities and fine arts students have some science 'core' requirements to fulfill; these are particularly important given the increasing role of technology in society, but again, close coupling of concepts are not required. As a result, 'humanistic engineering' programs which integrate engineering and humanities topics are being examined ${ }^{1}$. As a result of such a discussion at the University of Colorado, Boulder, that began in 2001 on 'Technology and Culture', faculty from engineering and from the humanities, including fine arts, were encouraged to propose joint courses. The present authors (Hertzberg and Sweetman) won a small award to pilot a laboratory/studio course on "Flow Visualization: the Physics and Art of Fluid Flow," which was taught in Spring 2003.

Proceedings of the 2004 American Society for Engineering Education Annual Conference \& Exposition Copyright C 2004, American Society for Engineering 
Making the connection between art and engineering has been hampered by the fact that fine arts studio courses are usually specifically excluded from satisfying a humanities requirement. ABET has recently relaxed this restriction ${ }^{3}$, but engineering faculty are still somehow offended by the idea of giving credit for purely creative work, fearing that students will sign up for mindless courses epitomized by 'basket weaving.' While there is no doubt that strict rigor is required for excellence in engineering, this exclusion of the aesthetic creative process from engineering curricula has likely contributed to a lack of diversity in engineering students. Truly creative individuals are limited to creativity in the context of utilitarian design projects and engineering problem solving techniques, or resort to double major status, if their finances allow. Aesthetics are sometimes mentioned in the context of engineering design ${ }^{4}$, particularly in bridge design ${ }^{5}$, but no research is available on the impact of aesthetics on engineering students. In a related approach, Felice Frankel's recent Envisioning Science 6 encourages scientists to create visually engaging images of their work. However, the idea of aesthetics as a motivation for science and engineering has not been explicitly addressed in the context of engineering education.

Thus, one important goal of our course was to expose students to an expression, an interpretation, of physics which cannot be accomplished verbally, but only visually. Many fluid physicists are motivated not only by the important scientific and engineering goals of their work, but also by a visceral fascination with their subject. Few scientists or engineers admit as such, but the existence of several venues for display of fluid flow art belie purely dispassionate motivations. Foremost among these venues is the Gallery of Fluid Motion ${ }^{7}$, a poster and video competition which held in conjunction with the American Physical Society Division of Fluid Dynamics (APS-DFD) annual fall meeting. Gallery entries are judged "based upon criteria of scientific merit, originality, and artistry/aesthetic appeal." Winners are published in a peerreviewed journal, Physics of Fluids, and winners for the past 17 years have been recently collected into a volume ${ }^{8}$. A recent New York Times article ${ }^{9}$ about the Gallery attests to the potential for general impact on students and the public. Additional examples include the seminal Album of Fluid Motion ${ }^{10}$, which can be found on the bookshelf of nearly every fluid dynamics researcher, and the recent Multi-Media Fluid Mechanics $C D-R O M^{11}$. In each of these examples, the sheer beauty of fluid flow is revealed and acknowledged to some extent. Thus we hope to encourage students to gain a deeper perception of fluid flow by capitalizing on this previously unacknowledged motivation, that is, for aesthetic and creative purposes. Not all students will continue in their study of fluids, but may instead become more open to an aesthetic appreciation of, and motivation for, other fields of science and engineering. Such a personal motivation may lead to life-long learning ${ }^{12}$, an elusive ABET goal.

\section{Course Structure}

The flow visualization course was offered in Spring 2003 to a group of mixed engineering and fine arts photography majors, and was co-taught by Professors Hertzberg and Sweetman. Of 42 students approximately $1 / 3$ were fine arts students and $2 / 3$ engineers. Of the engineers, $40 \%$ were graduate students, and the rest were seniors. These ratios were predetermined by enrollment limits.

Proceedings of the 2004 American Society for Engineering Education Annual Conference \& Exposition Copyright (C) 2004, American Society for Engineering 
Students were put on mixed teams of 3-5 students, chosen by the instructors to distribute technical strength in engineering and photography throughout the groups. Two major assignments were team assignments. The team approach worked well in most cases, allowing a couple of students to focus on producing the flow and visualization techniques, and the rest to focus on the photographic elements. Both engineering and art students reported positively on the interaction with the other discipline. The team approach had other benefits as well. Several of the graduate students were research assistants on projects with flow visualization equipment which were made available to their teammates. For example, one of the students had access to a large flume and a laser induced fluorescence system in the Civil Engineering department. Another student was studying flame treatment of plastic films with a large color schlieren system, and a third was interested in the aerodynamics of Olympic ski jumping, as part of a project to design new hills. Art students made sophisticated photographic equipment available to their teams, although there was still a pressing need for digital cameras and printers. (Digital photography was favored by the engineering students for the relatively low cost of processing).

The course was offered as a technical elective to the engineering students, and as studio credit to the fine arts students. Interestingly, several of the arts students wanted to register for the engineering section in order to get core science credit for the course. The course was structured as a lecture, with the actual image acquisition assigned as homework. This created two problems: 1) difficulties for the teams in finding time to work together, and 2) difficulty in providing hands-on instructor/TA support. In the future formal lab/studio sessions will be scheduled.

\section{Course Content}

The textbook was An Album of Fluid Motion ${ }^{10}$, chosen for its wealth of examples. An added benefit was the relatively low cost of the paperback edition since students were already responsible for the expense of photographic supplies.

There were four lectures on basic photographic techniques: optics, exposure, resolution, composition. This was primarily for the benefit of the engineering students, many of whom had little or no photography experience. Emphasis was placed on the quantitative aspects of optics and the interrelationship of spatial and temporal resolution in the measurement of fluid flows. There was also a guest lecture from a specialist on digital imaging technology.

There were 6 lectures on flow visualization techniques for gas and liquid flows, including a guest lecture on laser induced fluorescence. Three additional lectures on fluid physics included a survey of fluid phenomena, the use of nondimensional parameters, and a guest lecture from the National Center for Atmospheric Research on the physics of clouds. After the cloud lecture students would routinely come to class with observation reports of mountain wave rotor clouds, Kelvin-Helmholtz shear instabilities and the Crow contrail instability.

The art component consisted of four lectures on the history of photography, with emphasis on its evolution from science to art. We also discussed 'what makes an image art?' 'What makes an image science?' The consensus was that the answer to the latter is easy: any image of fluid flow can be considered science if the conditions of the fluid flow and the image acquisition and production process are known. The answer to the former was, of course, a matter

Proceedings of the 2004 American Society for Engineering Education Annual Conference \& Exposition Copyright (C) 2004, American Society for Engineering 
of personal interpretation. Despite the light treatment of art in the formal lectures, images produced by the students are unarguably artistic, as seen below.

\section{Assignments and Evaluation}

The first assignment, named "Get Wet", was designed to encourage students to explore small scale 'kitchen' flows, and to get the engineering students familiar with photography. On the first day of class, students were issued a blunted syringe and a length of $1 / 16^{\text {th }}$ inch diameter tubing, and were introduced to the concept of dye visualization. This assignment was made to individuals, and also served to demonstrate the importance of teamwork to the art students, who were used to working solo. Generating an effective fluid flow and imaging it simultaneously is quite challenging. After the assignment everyone was eager to form teams. Nevertheless, the class produced an astonishing array of flows and images. Figure 1 demonstrates the behavior of a buoyant jet (dyed alcohol) rising through a stratified interface (between water and corn syrup). Figure 2 shows the air-water interface formed by a vertical vortex whose core terminates at the surface. The vortex was created by hand, using an egg beater, and the flow was visualized using a fluorescent marker (All Detergent), excited by a UV light source.

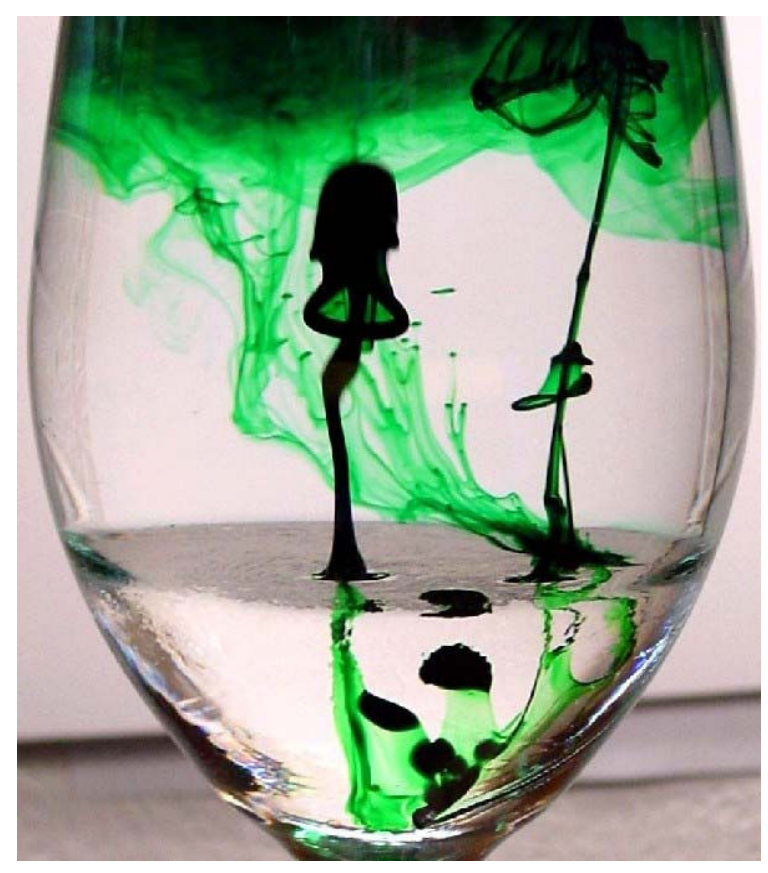

Figure 1: Buoyancy Through Interface. A buoyant jet of dyed 70\% isopropyl alcohol rises through the interface formed by corn syrup and water. Jessica Todd.

Since the first assignment was so successful in terms of the creativity displayed, students were assigned to develop their concepts further in an individual assignment due at the end of the semester. Two intermediate assignments were to photograph the fluid physics of atmospheric clouds. The remaining two assignments were major projects, assigned to teams. 


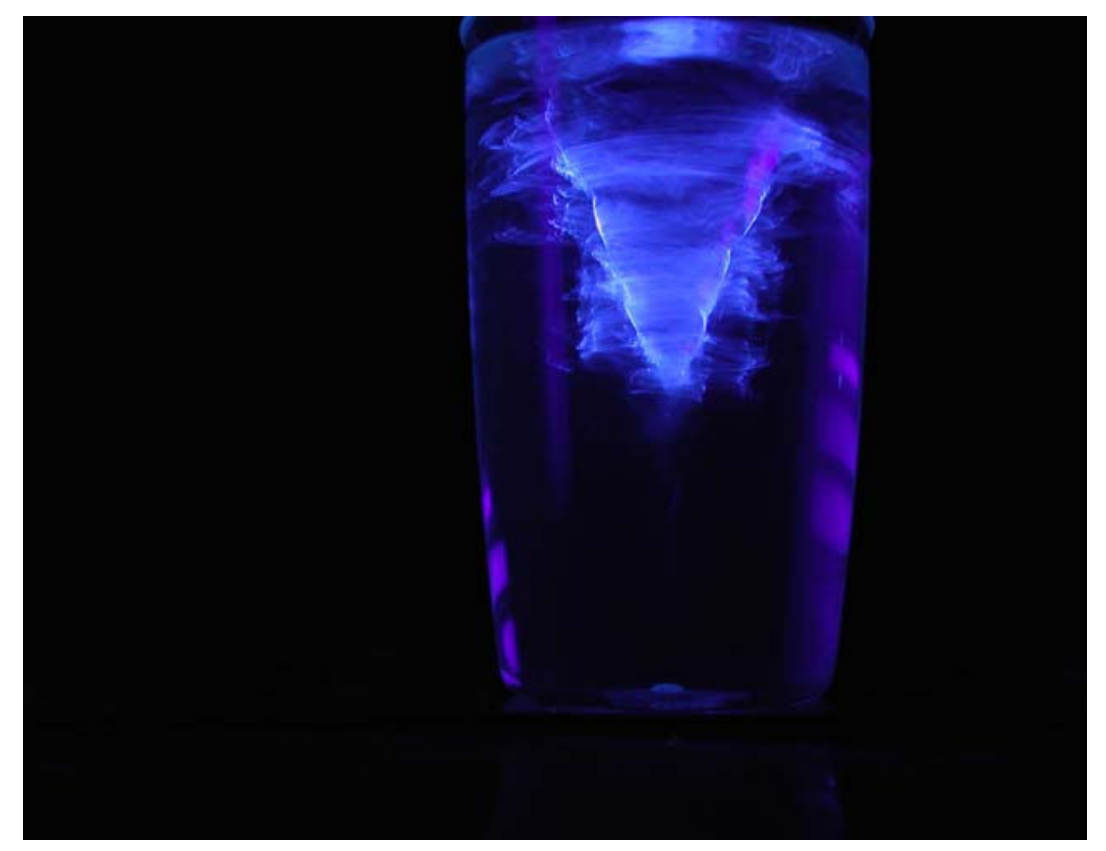

Figure 2: All Vortex. A vortex was formed manually, using an egg beater in a circular cylinder. A fluorescent marker (All laundry detergent) was added from above and excited by UV light. Geoffrey Hill.

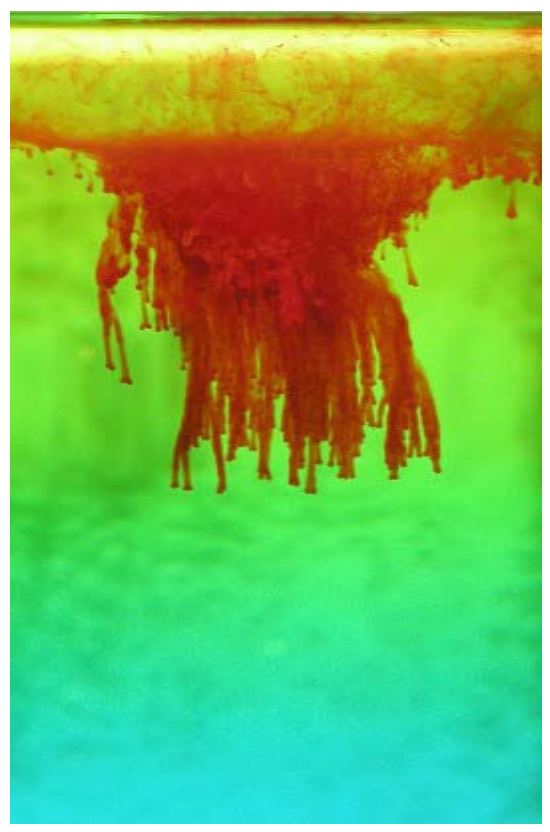

Figure 3: Negatively buoyant dye (food coloring) in water. Bethany Rotherham.

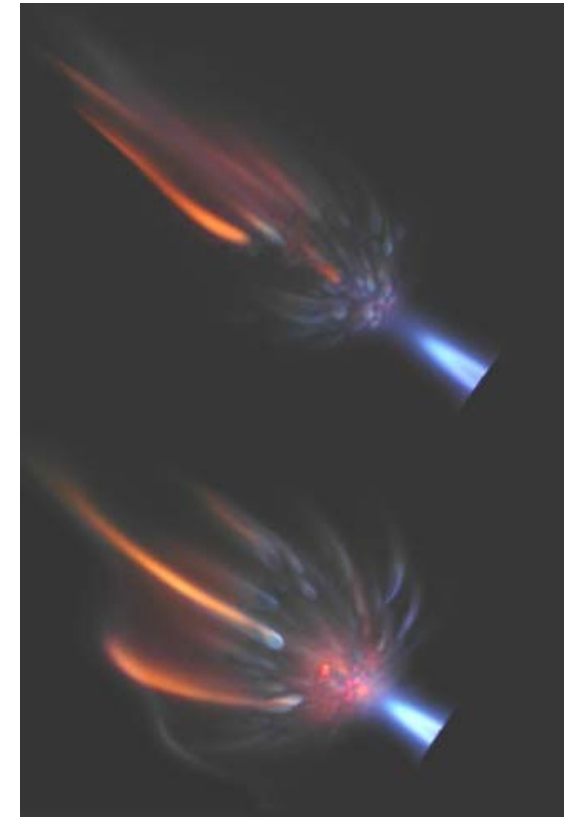

Figure 4: Butane torch impinging on an orange. Note the ablation of the surface at the stagnation point, and the ejection of fluid from pores. Dustin Grace. 
For the projects, students were given access to instructional and research flow facilities in the College of Engineering in addition to the facilities associated with graduate student research (described above). These included an open channel flow flume in our Integrated Teaching and Learning Laboratory, a 6 inch diameter vortex ring generator driven by a loudspeaker, a 50 gallon aquarium tank, and an Aerolab High Speed $0.5 \mathrm{~m} \mathrm{X} 0.5 \mathrm{~m}$ cross section wind tunnel. Not all of these facilities had flow visualization techniques already developed for them. For example, the flume required a controllable dye injection system. The wind tunnel is an open circuit tunnel

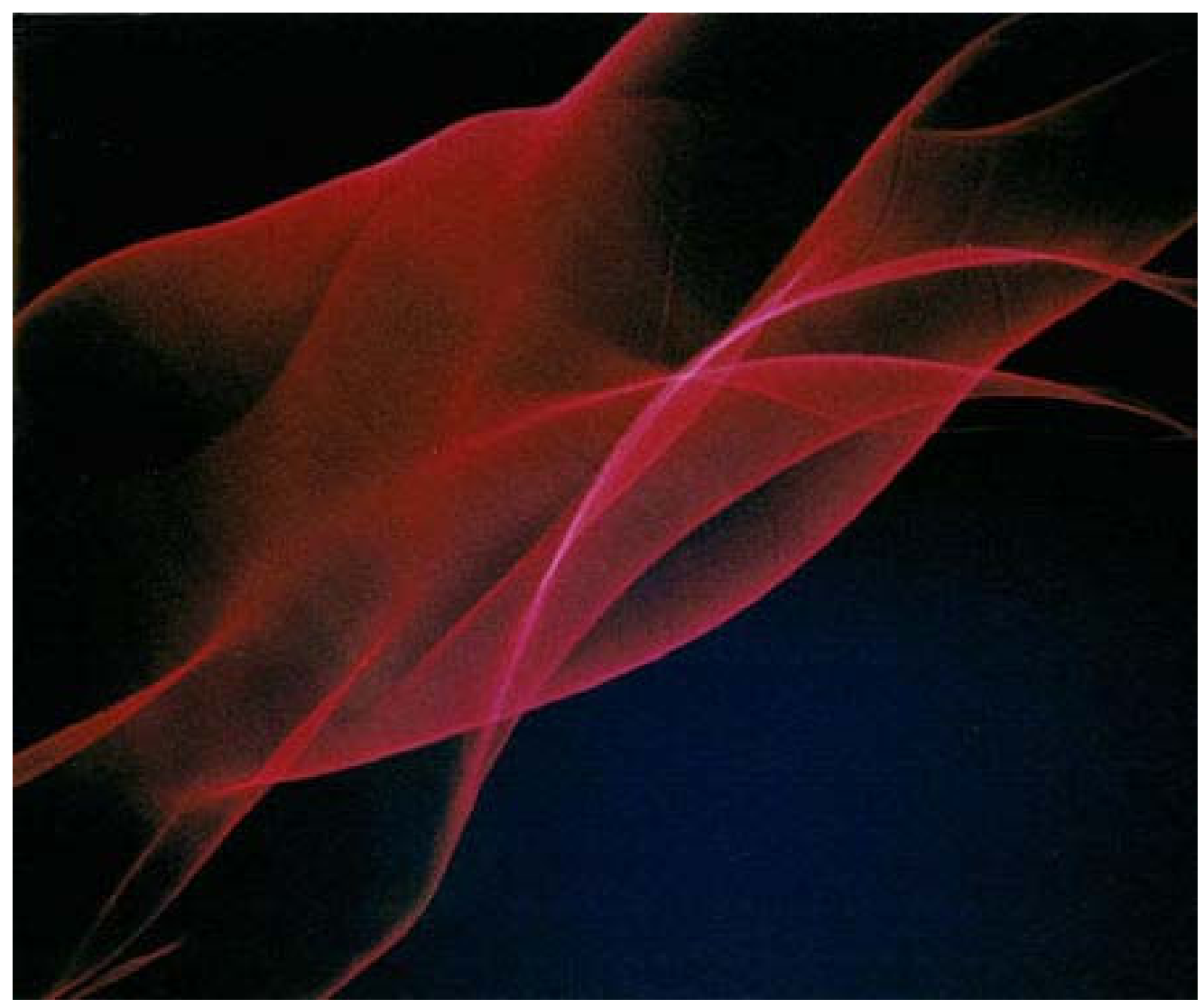

Figure 5: String in Turbulence. A timed exposure reveals the motion of three $1.5 \mathrm{~mm}$ diameter strings in the turbulent flow generated by a box fan.

Brianne Hovey, Jason Campbell, Nate Lee, Derek Paul, Kate Schwerin.

in a large laboratory, precluding the use of smoke visualization. Development of visualization hardware for some of these facilities was found to be outside the scope of the course as structured, with the present emphasis on the creation of images. In the future, these facilities will be developed as student projects via independent study, capstone design projects and paid assistantships.

Students were more successful with small scale equipment, and they independently developed a number of innovative materials and unusual flow phenomena. For example, 
negatively buoyant plumes have typically been studied in isolation. Figure 3 shows the behavior of such plumes en masse. In another example, students were interested in photographing combusting flows. The impingement of a butane torch on a flat surface was suggested to them, but instead they had the torch impinge on an orange. Figure 4 shows the ablation of the orange skin, as well as the combustion of small jets of orange oil forced from pores in the skin. Figure 5 is a timed exposure of four red strings moving in the turbulence generated by an axial flow fan.

Even when imaging more classic flows and materials, interesting approaches were used. Figure 6 shows the Saffman-Taylor instability in a Hele Shaw cell. Dyed glycerin was pressed between $(30 \mathrm{~cm})^{2}$ acrylic sheets. Water was injected through a $3.2 \mathrm{~mm}$ orifice, displacing the glycerin. The interface between the two fluids formed 'fingers' due to the Saffman Taylor instability. Typical images of this flow are made in black and white, and the interface between the fluids is sharp, in keeping with the corresponding two dimensional modeling approach. However, in this image, due to viscous effects at the walls, not all of the glycerin was displaced from an area, resulting in the color gradients behind the front. Figure 7 illustrates the bounce of a droplet hitting a liquid surface. Here dye adds interest and information to the image, which was actually made in a toilet bowl.

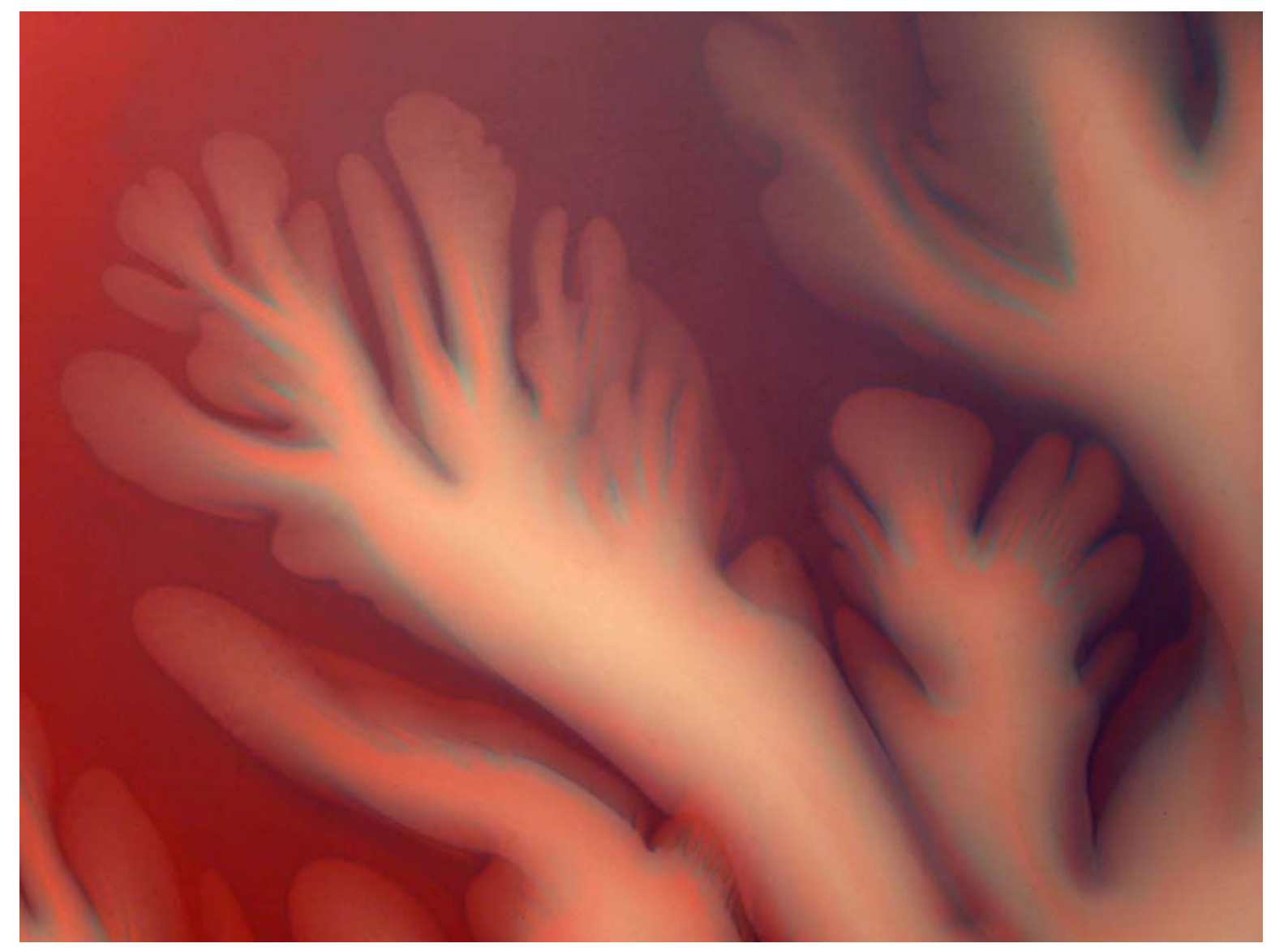

Figure 6: Saffman-Taylor Instability in a Hele Shaw Cell. Marilyn Poon, Jessica Todd, Robert Neilson, Dustin Grace. 
Students were evaluated in four categories for each assignment: art, flow, photographic technique and documentation. The first category was loosely graded for whether the intent of the image was realized and whether the image was effective. Flow was evaluated based on how clearly a flow phenomenon was illustrated. The criteria for good photographic techniques were proper exposure, focus, resolution and presentation. The accompanying report was to describe the intent, the phenomenon, and the photographic technique and was evaluated for content and clarity. Documentation was emphasized, to the shock of the art students, who had never been asked to produce such detailed reports before. However, expectations for student performance varied. Graduate engineering students were expected to provide more insight into the flow physics than undergraduate or art students, as well as a short literature search. Photography majors were expected to produce professional quality image production and mounting. A detailed rubric was developed describing the above criteria.

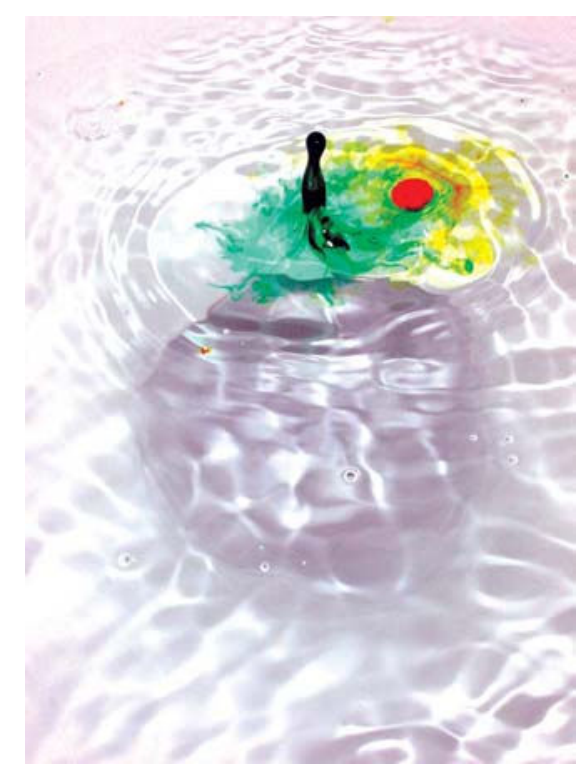

Figure 7: Drop. Dye (food coloring) is dropped into a pool disturbed by previous droplets. Blake Nolan.

Although the goal of student evaluation was clear, implementation was difficult, requiring a great deal of instructor time and effort. As a result, the evaluation process evolved throughout the semester. Initially, class critiques were held and students were expected to critique each others' work, and then submit their work for faculty evaluation. This process was hampered by the students' unwillingness to offer criticism, and the extensive time requirement for faculty to evaluate each student's project. The process then evolved into one where students prepared detailed self-evaluation, working from a check-off sheet derived from the rubric. During an in-class critique session, students viewed all the work, then the faculty discussed selected images as examples of quality in one or more category. Faculty then collected the work and reviewed the self-assessments. 
Student work has been presented to the public in a number of ways. At the end of the semester, a public show of the students' work was held in the lobby of the CU Engineering Center. Figures 1, 2, 5 and 6 were entered in the most recent Gallery of Fluid Motion competition; Figure 5 was one of the winners. Additional student images are available online, along with additional course information at http://www.colorado.edu/MCEN/flowvis/ . In March 2004, a formal show of student images has been scheduled for the Boulder Museum of Contemporary Art as part of a program on "The Art of Science in Culture."

\section{Outcomes and Conclusion}

One notable outcome was the students' use of environmentally benign materials. CU Boulder has a very strict policy of 'no chemicals down the drain.' This policy makes the use of some traditional flow visualization materials such as acid/base indicators and fluorescent dyes problematic in large flow facilities. Students responded by experimenting with materials such as food coloring, non-toxic stage fog, fluorescent detergents and highlighter ink, and pearlescent shampoo instead of commercial rheoscopic fluids.

Another outcome was seen in the demographics of the students that chose the course. The class was oversubscribed, with a substantial wait list, indicating the initial popularity of the course concept. What was surprising was the popularity of the course with women students. Of the undergraduate engineering majors, $29 \%$ were women, approximately twice the fraction in our student population. Of the graduate engineering students this effect was more pronounced with 42 percent women, nearly three times that of the population. Even among the fine arts students, $58 \%$ were women, compared to $50 \%$ in fine arts overall. This suggests a new approach to increasing the participation of women in mechanical engineering. Mechanical engineering is viewed as a dry, solid-mechanics (gears, levers) - oriented, and perhaps overly utilitarian discipline. Partly due to this perception, the participation of women in ME is very low. Nationwide, enrollment of women in ME has not climbed above $14 \%$ of the undergraduate student population in the past 10 years, and is increasing very slowly ${ }^{13}$. This small percentage translates into a low fraction of women mechanical engineers in the workforce, approximately $6.5 \%{ }^{14}$. Specifically in the area of fluid flow research, the female membership of the APS-DFD, is approximately $7 \%$, which is slightly lower that the overall APS membership at $10 \%{ }^{15}$. Since this course has a demonstrated appeal to women, a useful approach may be to promote the novel aspects of this course, i.e. creative aesthetics, combined with techniques proven to improve diversity, such as hands-on and team oriented ${ }^{16}$.

The final outcome was made apparent in spontaneously offered comments:

"These images are from mechanical engineers? I thought mechanical engineers were just stiff, boring, ugly and male." -Female final exhibit viewer.

"I had an epiphany while watching incense smoke the other night. What I was seeing was light scattered by soot particles moving with the air that was rising due to heating by the burning incense. I had always just seen 'smoke' before." -Rayna Tedford, Fine Arts Photography Masters' student. 
"I'll never be able to ignore the sky again." -Sanjeev Sharma, Mechanical Engineering Masters' student.

The first comment speaks to the common perception of mechanical engineers, and suggests that publication of student images may be an approach to moderating this perception. Certainly future offerings of the course will include similar public showings, student work is available on the web, and a publisher for a series of posters is being sought. However, widespread impact directly from this course is unlikely to occur. Instead, this course represents a radical departure from traditional engineering curricula in its integration of art and engineering, and is likely to serve as a model for similar courses, whose net impact may be significant. It has already served as a model for a course on Art and the Environment, being offered here at CU in Spring 2004. After a presentation on the course at the Fall 2003 APS-DFD meeting, the author was approached by faculty from four other institutions (Harvey Mudd, U. Penn., Penn. State and Georgia Tech.) who expressed an interest in offering a similar course, as well as by several students who wished their institution offered such a course.

The last two comments address an impact on student perceptions of the world around them. The photography student was a Master's candidate, and already highly trained in the type of observation required for photography. Nevertheless, the course enabled her to see the physics in her surroundings. Similarly, the perceptions of the engineering student were broadened to include the beauty of everyday fluid flows. These comments suggest that the class has had an impact on these students "motivation for life-long-learning," since perception is a necessary first step to understanding. More direct assessment of this motivation is planned for future course offerings.

\section{Acknowledgements}

The authors wish to thank the students who contributed so creatively. Note that the images reproduced here are published online at http://www.colorado.edu/MCEN/flowvis. We also want to thank Erik Fisher for his leadership in bringing our disparate cultures together, and the CU Boulder administration for supporting this project.

\section{References}

1 "The CDIO syllabus: a comparative study of expected student proficiency". Bankel, Johan, Berggren, KarlFredrik, Blom, Karin, Crawley, Edward F., Wiklund, Ingela Östlund, Sören. European Journal of Engineering Education; Vol. 28, Issue 3, p297, 19p, Sep2003.

${ }^{2} \mathrm{http}: / / \mathrm{www}$.colorado.edu/ArtsSciences/CHA/techculture.htm

${ }^{3}$ Engineering Accreditation Commission, "Criteria for Accrediting Engineering Programs 2003-2004," Accreditation Board for Engineering and Technology, http://www.abet.org/criteria eac.html

4 "Technological Allusivity: Appreciation and Teaching in the Role of Aesthetics in Engineering Design," Adams, C.C., Proceedings of the 1995 ASEE/IEEE Frontiers in Education Conference, Vol.1, pp 3a5.1-8.

${ }^{5}$ The Art of Structural Design: a Swiss Legacy, David Billington, Princeton University Art Museum, 2003.

${ }^{6}$ Envisioning Science, Felice Frankel, MIT Press, 2002.

${ }^{7}$ http://www.aps.org/units/dfd/ 
${ }^{8}$ A Gallery of Fluid Motion, M. Saminy K. Breuer, G. Leal, P. Steen. Cambridge University Press, 2003.

9 "From Flowing Fluids, Beautiful Images and Unlocked Secrets," Bruce Schechter, New York Times, June 24, 2003.

${ }^{10}$ An Album of Fluid Motion, Van Dyke ed. Parabolic Press, 1982.

${ }^{11}$ Multi-Media Fluid Mechanics CD-ROM, G. M. Homsy, H. Aref, K. S. Breuer, S. Hochgreb, J. R. Koseff, B. R. Munson, Cambridge University Press, 2000.

12 "Lifelong Learning: a Preliminary Look at the Literature in View of EC2000," R.M. Marra, K.Z. Camplese, T.A. Litzinger. Proceedings of the 1999 ASEE/IEEE Frontiers in Education Conference, pp 11a1-7.

${ }^{13}$ Engineering and Technology Enrollments 2003 Report, Engineering Workforce Commission, American Association of Engineering Societies.

${ }^{14}$ US Department of Labor, Bureau of Labor Statistics. Highlights of Women's Earnings in 2002. Report 972, Sept. 2003. http://www.bls.gov/cps/cpswom2002.pdf

${ }^{15}$ Private communication, Sue Otwell, Office of Minority Programs, American Physical Society, 11/2/2003.

${ }^{16}$ Knight, D.W., Carlson, L.E. and Sullivan, J.F. (2003), "Staying In Engineering: Impact Of A Hands-On, TeamBased, First-Year Projects Course On Student Retention," CD-ROM, Proceedings, American Society for Engineering Education Annual Conference, June 2003, Paper 1800. (Selected Best Conference Paper). http://itll.colorado.edu/ITLL/Templates/ITLInTheMedia/Papers/ASEE\%2003\%20Retention\%20GEEN\%201400\%2 0Proceedings.pdf

\section{Biographical Information}

\section{JEAN HERTZBERG}

Jean Hertzberg is an Associate Professor of Mechanical Engineering at CU Boulder. She received her B.S in ME from the University of Michigan, Ann Arbor, and M.S and Ph.D. in ME from the University of California, Berkeley. Her research is in experimental fluid dynamics, with an emphasis on vortex dominated flows for combustion and cardiovascular applications. She is also an avid amateur photographer.

\section{ALEX SWEETMAN}

Alex Sweetman is a Professor of Fine Arts at CU Boulder. His B.A. is from New York University, Washington Square College, and M.F.A. is from the SUNY Buffalo, Program in Photographic Studies, Visual Studies Workshop. His creative work is in the area of studio photography, with over one hundred exhibitions, and more than thirty solo exhibitions. His research is in visual studies, especially the history and theory of visual media. 